\title{
FACTORES DE RIESGO DE CONTAMINACIÓN DE LA LECHE CON BACTERIAS ESPORULADAS (CLOSTRIDIUM) EN ESTABLECIMIENTOS LECHEROS DE LAPROVINCIADE SANTAFE
}

\author{
Thomas, J. ${ }^{1}$; Dalla Fontana, L. ${ }^{1}$; Ramos, E. ${ }^{2}$; Thomas, J. ${ }^{2}$; DemariA, M. ${ }^{2}$; \\ Costamagna, D. ${ }^{3}$; Faggiano, M. $^{3} \&$ Bonzi, E. ${ }^{1}$
}

\begin{abstract}
RESUMEN
Un estudio exploratorio de contaminación en leche de tanque con esporulados (Clostridium) en 20 tambos (Pcia.de Santa Fe), con silaje la mayor parte del año (2 muestreos/tambo, Otoño 2010), indica alta proporción de cisternas contaminadas. El análisis estadístico de factores de riesgo de contaminación en 9 establecimientos (higiene del tambo y ordeñe -calidad, extracción y distribución del silajecontaminación en heces) desde Otoño 2010 a Otoño 2011, indican la diferencia entre estaciones, con y sin silaje (primavera) y demuestra que el mayor riesgo de contaminación con clostridios proviene de la alimentación con silaje de pobre calidad. Los tambos analizados con: silaje de buena calidad, alta tecnología de extracción y distribución del alimento, alta higiene de las vacas y del ambiente del tambo, y alta higiene del pezón durante la rutina de ordeño, lograron bajas concentraciones de esporas / l de leche $(<200 \mathrm{NMP} /$ litro) y bajas concentraciones de esporas $/ g$ de heces $(<10.000 \mathrm{NMP} / \mathrm{g}$ heces $)$.

Palabras claves: Clostridium, leche de tanque, silaje .
\end{abstract}

\section{SUMMARY}

Risk factors for bulk tank milk contamination with spore-forming bacteria (Clostridium) in Santa Fe dairy farms.

The exploratory study of bulk milk contamination with spores (Clostridium) in 20 dairy farms (Santa Fe Province) with silage feeding most of the year (2 samples/farm, fall 2010) indicates a high proportion of contaminated tanks. Statistical analysis of risk factors of contamination in 9 farms (dairy and milking hygiene -quality, extraction and distribution of silage- dung contamination) from fall 2010 to fall 2011, indicates: differences between seasons-with and without silage (Spring), and

1.- Facultad de Ciencias Agrarias (UNL). Kreder 2805. (3080) Esperanza, provincia de Santa Fe. Email: jthomas@fca.unl.edu.ar

2.- Instituto Nacional de TEcnología Industrial. Ruta Nacional 34. Km. 227.6. (2300) Rafaela, provincia de Santa Fe.

3.- Alumnos Adscriptos a las Cátedras de Forrajes y Producción de leche (FCA - UNL).

Manuscrito recibido el 6 de diciembre de 2012 y aceptado para su publicación el 17 de mayo de 2012 . 
confirms that the increasing risk of contamination with Clostridium comes from feeding poor quality silage. Those dairies with good quality silage, high technology of extraction and distribution of silage, high hygiene of cows and the environment, and high teat hygiene during the milking routine, achieve low concentration of spores/l of milk $(<200 \mathrm{MPN} / \mathrm{I})$ and low concentration of spores/g of faeces (<10.000 MPN/g faeces).

Key words: clostridium spores, bulk tank milk, silage.

\section{INTRODUCCIÓN}

El control de la contaminación de la leche con organismos esporulados generadores de gas butírico, resulta importante para la industria láctea en relación al defecto de hinchazón tardía en quesos, siendo los más susceptibles los de pasta dura y semidura. Los responsables de esta contaminación microbiológica de interés para la industria casearia, son las bacterias anaerobias formadoras de esporas Clostridium tyrobutyricum y $C$. butyricum las cuales fermentan azúcares y ácidos orgánicos. Su capacidad de sobrevivir a la pasteurización les permite crecer durante el proceso de maduración de los quesos, originando defectos de sabor y excesiva formación de gas. La contaminación de la leche con niveles tan bajos como $0.01 \mathrm{UFC} / \mathrm{ml}$ puede causar el defecto mencionado en ciertos tipos de quesos como el Gouda (Bergere \& Hermier, 1970; Klijn et al., 1995).

Las nuevas regulaciones para la inocuidad de los alimentos, requieren del productor la responsabilidad de garantizar que los alimentos que consume el ganado se encuentren libres de contaminantes. La seguridad de que se podrán controlar los peligros y mejorar la calidad del producto dependerá de que todos los pasos en el proceso de producción hayan sido incluidos en este control (Weissbach, 2006).

La intensificación de la producción lechera genera mayor uso de algunos recursos forrajeros como el silaje. Siendo este alimento, ofrecido en raciones mixtas, el que más contribuye a la contaminación de la leche con bacterias formadoras de esporas (Clostridium y Bacillus), y parece convertirse actualmente en un serio problema para la industria láctea.

La utilización de silaje de baja calidad para la alimentación de las vacas en lactancia, aparece como uno de los factores más importantes que contribuye a esta contaminación. Las heces son consideradas la principal vía de contaminación hacia la leche (Bergere $e t$ al., 1968).

Cuando los alimentos utilizados son otros diferentes al silaje, o la mezcla de la ración no contiene silaje, las prácticas de higiene consideradas normales para la rutina de ordeño pueden ser suficientes para alcanzar el nivel deseable de calidad en leche de tanque. Cuando la fracción del silaje en la ración supera el $50 \%$, los riesgos de incremento en el nivel de contaminación en tanque de leche son mayores (Vissers et al., 2006).

Las esporas están naturalmente presentes en el suelo, pero las prácticas de manejo utilizadas, tanto para el silaje, como para otros alimentos, incluyendo el heno, pueden actuar como una fuente de contaminación de bacterias productoras de ácido butírico (Vissers et al., 2006).

El contenido de materia seca y $\mathrm{pH}$ del silaje durante el período de confección, han sido identificados como importantes factores para 